\title{
Palabras previas. Actas Congreso 70 aniversario DUDH en CEFD Foreword. Conference Proceedings Congress 70th anniversary DUDH in CEFD
}

\author{
Javier de Lucas \\ Director. Instituto de Derechos Humanos \\ Universitat de València
}

Quiero agradecer a la profesora Maria José Añón, Directora de la prestigiosa revista Cuadernos Electrónicos de Filosofía del Derecho (CEFD) y al profesor Andrés Gascón, Secretario de la misma, su ofrecimiento para albergar en este número monográfico las actas del Congreso sobre el 70 aniversario de la Declaración universal de derechos humanos (DUDH), organizado por el Instituto de Derechos Humanos de la Universitat de Valencia (IDHUV).

Permítase que explique los antecedentes de este Congreso, que ha sido hasta ahora el evento de mayor entidad organizado por el IDHUV. En octubre de 2017 propuse a los compañeros de nuestro IDHUV que hiciéramos un esfuerzo para conmemorar los acontecimientos que marcaban 2018 como un "año de derechos": se trataba de un lado de los 40 años de la Constitución española de 1978 y, de otro, del 70 aniversario de la DUDH. Una excelente oportunidad para un año para cumplir con una de las misiones fundacionales de nuestro Instituto, contribuir a lo que llamamos "cultura de los derechos".

Comenzamos ese año 2018 con una publicación realizada por profesores de nuestro IDHUV, destinada a la divulgación de esa <cultura de los derechos>, el libro Per qué els drets humans, destinado a profesores y estudiantes de educación secundaria. En segundo lugar, fruto de la colaboración de profesores de nuestro IDHUV y del Instituto de Derechos Humanos Bartolomé de las Casas, de la Universidad Carlos III, pudimos presentar en el mes de noviembre el libro Constitución y derechos humanos. Ambos fueron publicados por la editorial Tirant Lo Blanch, la primera editorial jurídica en España en términos del impacto científico, y que ha acogido generosamente a lo largo de estos años esas publicaciones, también una colección de derechos humanos y apoyó el Congreso internacional. Finalmente, y como concreción del segundo objetivo, celebramos en Valencia, entre los días 10 y 12 de CEED Número 39 Publicación actas Congreso Internacional 70 Aniversario Declaración Universal de Derechos 
diciembre de 2018, un Congreso internacional con la participación de medio centenar de especialistas. Alcanzamos ahora el propósito lógico de ese esfuerzo, ver recogidas en una publicación buena parte de las contribuciones al mismo. Pero todo ello fue posible gracias a la ayuda que recibimos de diferentes personas e instituciones. Los que es de justicia reconocer.

El apoyo de la Generalitat fue decisivo para poder organizar el Congreso. En primer lugar, el del President de la Generalitat, honorable Ximo Puig. También el de la honorable Gabriela Bravo, consellera de justicia, administración y reformas democráticas.

Debemos agradecimiento al Rector de la Universitat de València, el Dr. Esteban Morcillo, por su acogida inmediata al proyecto del Congreso cuando se lo presentamos en enero de 2018, una acogida que reiteró calurosamente la nueva rectora de la Universitat de Valencia, la Dra. Mavi Mestre, que comprometió una ayuda especial para la realización.

Especial mención resrevamos a la Embajada de Canadá, en la persona de su Embajador Matthew Levin, un excelente amigo de nuestro Instituto, de nuestra Universidad y de Valencia. Todos en el Instituto sabemos del compromiso del Gobierno de Canadá y de su Embajada en España, de su trabajo ejemplar como un país empeñado en la defensa de la legalidad internacional, el multilateralismo y la garantía de los derechos humanos, también de los más débiles, como los refugiados. Fue una gran satisfacción que el profesor, ministro y ahora Embajador Stephan Dion aceptara asumir la conferencia inaugural. Esa contribución abre las actas que recoge este número de CEFD.

Sin el apoyo constante, la generosidad y el esfuerzo de la Fundación Canadá, no ya este Congreso, sino una parte considerable de los proyectos internacionales de nuestro Instituto no podrían ver la luz. Por eso, todo agradecimiento es poco a la doctora Esther Mitjans, Presidenta de la Fundación y a la directora de la fundación, gran amiga de la Universitat de València, Doña Marisa Calés.

El Congreso se realizó sobre todo gracias a la generosidad del medio centenar largo de conferenciantes y ponentes, moderadores y presentadores, de enorme prestigio en sus diferentes campos (académicos, institucionales, ONGs), distribuidos a lo largo de ocho paneles y seis conferencias. Las Actas recogen cuatro de las ponencias, comenzando por la inaugural del embajador y profesor Stéphane Dion, junto a la del profesor y Relator especial de la ONU, Fabián Salvioli, y las del Defensor del Pueblo de España 
(e.f.), Francisco Fernández Marugán y el Decano de Humanidades de la Universidad de Deusto, Eduardo Ruiz Vieytez, que se ocupan de cuatro cuestiones centrales del debate en torno a los derechos humanos: la amenaza del populismo, los nuevos paradigmas de paz y justicia, los defensores de los derechos y el debate en torno a la diversidad cultural. A continuación, se incluye una selección de las comunicaciones presentadas, agrupadas en seis bloques temáticos: violencia de género y derechos de las mujeres, empresas multinacionales, memoria histórica, nuevos escenarios y garantías, vulnerabilidades y perspectivas. La selección fue realizada por un Comité dirigido por el profesor Jose Antonio García Sáez.

Sería injusto terminar estas líneas de presentación sin reconocer y agradecer el trabajo del Comité organizador que, en definitiva, es el que ha permitido que llegásemos hasta esta publicación: muchas gracias a José Elías Esteve y Ana I. Roig, Germana Aguiar, Maria Dalli, Danai Delipetrou, Estrella del Valle, Jose A. García, Andrés Gascón, Olga Lenzi, Albert Mora, Amada Perales, Manuel Peris y Raquel Vanyo.

En esta prestigiosa universidad de Valencia, quiero expresar el placer que siento al pronunciar el discurso inaugural de una conferencia para destacar el $70^{\circ}$ aniversario de la Declaración Universal de Derechos Humanos. Mi presentación pondrá de relieve la importancia crucial de esta Declaración y abordará también el riesgo que representa para los derechos humanos el auge actual del populismo en las democracias liberales. Mis observaciones sobre el populismo van sobre todo a centrarse en el continente europeo, el cual incluye mis responsabilidades actuales como embajador de Canadá en Alemania y de Enviado Especial del primer ministro Trudeau ante la Unión Europea y Europa.

Después de haber subrayado la importancia de esta Declaración y el considerable progreso que la misma ha promovido desde el punto de vista del respeto de los derechos humanos, me referiré a las causas de la subida del populismo en Europa, sus consecuencias y los medios para remediar sus efectos negativos. 


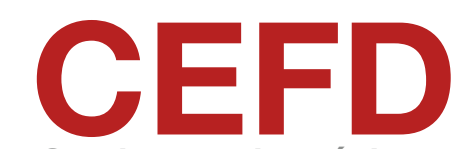

Cuadernos Electrónicos

de Filosofía del Derecho

CEFD Número 39 Publicación actas Congreso Internacional 70 Aniversario Declaración Universal de Derechos 